ISSUES IN MEDICINE

\title{
Herbal medicine, randomised controlled trials and global core competencies
}

\author{
N Siegfried, G Hughes \\ Nandi Siegfried and Gail Hughes are affiliated to the South African Herbal Science and Medicine Institute at the University of the Western Cape \\ in Bellville, Cape Town. Nandi Siegfried is also affiliated to the Department of Psychiatry and Mental Health at the University of Cape Town and \\ the Department of Epidemiology and Biostatistics, University of California, San Francisco, and Gail Hughes to the School of Allied Health Sciences, \\ University of Missouri.
}

Corresponding author: G Hughes (ghughes@uwc.ac.za)

\begin{abstract}
Despite widespread use, few empirical data on the efficacy of traditional medicine are available. We conducted systematic reviews of eight widely used African medicines and identified only one plant, Pelargonium sidoides, which has been extensively studied (including in a Cochrane systematic review). To address the need for rigorous science to underpin traditional medicine claims, the South African Herbal Science and Medicine Institute at the University of Western Cape launched the Multi-disciplinary University Traditional Health Initiative (MUTHI) in 2011. The European Union-funded initiative aims to build sustainable research capacity on plants for better public health in Africa. A 2011 needs analysis of clinicians and scientists from 14 African countries confirmed a lack of clinical trial methodology, knowledge and experience. In response, MUTHI deliverables include annual clinical trial methodology workshops in host countries and development of e-learning modules. The initiative provides a unique opportunity for developing African capacity to discover new medicinal products.

S Afr Med J 2012;102(12):912-913. DOI:10.7196/SAMJ.6392
\end{abstract}

In his editorial in the SAMJ of March 2012, Professor Van Niekerk clearly describes the differences between traditional and allopathic medicine based on their fundamental ways of knowing. ${ }^{1}$ Traditional medicine is centred in the domain of mystica (belief, religion); allopathic medicine lies within the domain of empirica (research). He acknowledges that modern medicine has evolved from a system of beliefs, traditionally adopting and refining natural remedies observed to contain successful medicinal properties in the field. Research, in particular the use of the randomised controlled trial, should drive the process to identify efficacy, non-efficacy and potential harm of all potential medicinal products including so-called traditional remedies. ${ }^{2}$

The World Health Organization indicates that up to $80 \%$ of African populations use traditional medicine, and similar figures have been reported in South Africa (SA). ${ }^{3}$ Therefore, sufficient attention is required for a better understanding of the safety, efficacy and practice of African traditional medicine in clinical trials. To date, there has been limited scientific documentation on the use of traditional medicine, especially randomised clinical trials, but literature reporting on prevalence, and case studies and case reports, have been noted. ${ }^{4,5}$

Synthesis of results from randomised trials in the form of systematic review and meta-analysis can provide clinicians and policymakers with the evidence necessary for clinical and regulatory healthcare decision-making. ${ }^{6}$ We conducted systematic reviews of eight widely used African traditional plant medicines, and identified only one (Pelargonium sidoides), which has been extensively studied in human trials albeit none of these on the African continent. ${ }^{7}$ We identified three published trials of plants conducted in Mali ${ }^{8,9}$ and Nigeria, ${ }^{10}$ a report of two unpublished trials, ${ }^{11}$ and one unconfirmed trial. Encouragingly, two plant products (P. sidoides and Niprisan) have been evaluated in Cochrane systematic reviews. ${ }^{72}$ In the HIV/AIDS field, the first local safety randomised controlled trial of Lessertia frutescens (colloquially known as Sutherlandia) was published in $2007 .{ }^{13}$ Despite being widely used as an immune booster, there is little scientific evidence either for or against its benefit; a phase $2 \mathrm{~b}$ clinical trial is in preparation (personal communication).

Within SA, and across the continent, there is an active and growing community of scientists and traditional healers that recognises the need for rigorous science to underpin any claims made in favour of traditional medicines. The Multi-disciplinary University Traditional Health Initiative (MUTHI) is a European Union-funded project that aims to build sustainable research capacity on plants for better public health in Africa. Running for four years, MUTHI comprises a consortium of universities with four institutions based in Africa (University of Bamako in Mali, University of Makerere in Uganda, and the Universities of the Free State and Western Cape (UWC) in South Africa) and three based in Europe (Universiteit van Amsterdam in The Netherlands, Universitetet I Bergen in Norway, and the University of Oxford in the UK). The project comprises five work packages, each with a focus on a different aspect of the research process required for herbal medicine development. Work packages include ethnobotany, laboratory techniques, intellectual property rights and training in clinical trials. The South African Herbal Science and Medicine Institute, UWC, is the lead institution tasked with training African investigators in clinical trials methodology.

Prior to implementing MUTHI training in 2011, we conducted a training needs assessment of clinical and public health researchers in African universities who were planning to conduct clinical research on herbal medicines. ${ }^{14}$ Fifty-seven respondents from 35 institutions in 14 African countries identified resource constraints, lack of herbal medicine supplies, lack of trained staff, and logistical issues as the main obstacles in conducting trials of herbal medicines. They requested further training in ethics, statistical analysis, protocol design, monitoring and reporting, and publishing of trial results. 
These capacity deficiencies mirror those identified in a 2008 SA-focused needs assessment of key stakeholders in the allopathic clinical trial landscape. ${ }^{15}$ The picture is no different globally. In a 2011 report published under the auspices of the Organization of Economic Co-operation and Development (OECD) Global Science Forum, stakeholders and experts from all over the world interviewed in a survey reported limited availability of accredited trial methodological training for members of the trial team, regardless of resource setting. ${ }^{16}$

To address the gap in trials capacity, MUTHI launched the inaugural Clinical Trials Workshop in Cape Town in November 2011. The content was guided by the needs identified in our survey, and participants were also exposed to Good Clinical Practice and Good Manufacturing Practice. Fourteen participants from 5 African countries (South Africa, Mali, Uganda, Sudan and Nigeria) were selected to attend after a competitive application process. Participants came from several disciplines including basic science, medicine, pharmacy and traditional medicine. Further workshops are planned for Mali and Uganda in 2013, and an e-learning course is under development.

The OECD has recommended the development of Global Core Competencies as a compendium of required knowledge and skills for investigators and other members of the clinical trials team, research ethics committees, regulatory bodies and trial sponsors. Standardised and mutually and internationally recognised accredited qualifications in patient-oriented research will be defined, connected to these Global Core Competencies. ${ }^{17}$ Specific issues related to intellectual property rights and benefit-sharing arise in clinical trials of herbal medicines, especially where communities are vulnerable to exploitation. Such Global Core Competencies, to have a truly global reach, will need to take cognisance of the need for training in these areas.

It is foreseeable that training in clinical trials methodology can provide an opportunity for bringing together those working in both traditional medicine and allopathic medicine in a learning environment. Our experience at MUTHI so far suggests that there is a great willingness to learn about the science of medical product development among health professionals interested in herbal medicines and those working as traditional healers. We agree with Van Niekerk that acceptance and respect of difference will smooth the path towards better collaboration with the potential of discovering new cures.

1. Van Niekerk J. Traditional healers formalised? S Afr Med J 2012;102(3):105-106.

2. Schulz KF. Unbiased research and the human spirit: the challenges of randomized controlled trials. CMAJ 1995;153(6):783-786.

3. Nxumalo N, Alaba O, Harris B, Chersich M, Goudge J. Utilization of traditional healers in South Nxumalo N, Alaba O, Harris B, Chersich M, Goudge J. Utilization of traditional healers in South
Africa and costs to patients: findings from a national household survey. J Public Health Policy. 2011;32 Suppl 1:S124-136.

4. Peltzer K. Utilization and practice of traditional/complementary/alternative medicine (TM/CAM) in South Africa. Afr J Tradit Complement Altern Med 2009;6(2):175-185.

5. Peltzer K. Traditional health practitioners in South Africa. Lancet. 2009;374(9694):956-957.

6. Egger M, Davey-Smith G, O’Rourke K. Rationale, Potentials, and Promise of Systematic Reviews. In: Egger M, Davey-Smith G, Altman DG, eds. Systematic Reviews in Health Care: Meta-analysis in Context. 2nd ed. London: BMJ Publishing Group; 2001:3-19.

7. Timmer A, Gunther J, Rucker G, Motschall E, Antes G, Kern WV. Pelargonium sidoides extract for acute respiratory tract infections. Cochrane Database Syst Rev. 2008(3):CD006323.

8. Willcox ML, Graz B, Falquet J, Sidibe O, Forster M, Diallo D. Argemone mexicana decoction for the treatment of uncomplicated falciparum malaria. Trans R Soc Trop Med Hyg 2007;101(12):1190-1198.

9. Graz B, Willcox ML, Diakite C, et al. Argemone mexicana decoction versus artesunate-amodiaquine fraz B, Willcox ML, Diakite C, et al. Argemone mexicana decoction versus artesunate-amodiaquine
for the management of malaria in Mali: policy and public-health implications. Trans R Soc Trop for the management of malara
Med Hyg 2010;104(1):33-41.

10. Wambebe C, Khamofu H, Momoh JA, et al. Double-blind, placebo-controlled, randomised cross-

over clinical trial of NIPRISAN in patients with sickle cell disorder. Phytomedicine 2001;8(4):252-261. 1. Whelan AM, Jurgens TM, Szeto V. Case report. Efficacy of Hoodia for weight loss: is there evidence to support the efficacy claims? J Clin Pharm Ther 2010;35(5):609-612.

2. Oniyangi O, Cohall DH. Phytomedicines (medicines derived from plants) for sickle cell disease. Cochrane Database Syst Rev. (10):CD004448.

3. Johnson Q, Syce J, Nell H, Rudeen K, Folk WR, A randomized, double-blind, placebo-controlled trial of Lessertia frutescens in healthy adults. PLoS Clinical Trials 2007;2(4):e16.

14. Willcox M, Siegfried N, Johnson Q. Capacity for clinical research on herbal medicine in Africa. Journal Willcox M, Siegfried N, Johnson Q. Capacity
Alt Complement Med 2012;18(6):622-688.

15. Siegfried N, Volmink J, Dhansay A. Does South Africa need a national clinical trials support unit? S
Alt Complement Med 2012:18(6):622-688. Siegfried N, Volmink J, Dhansay A.
Afr Med J 2010;100(8):521-524.

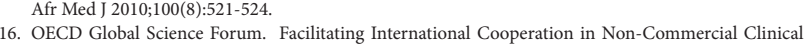
16. OECD Global Science Forum. Facilitating International Cooperation in Non-Commercial Clinical
Trials, October 2011. http://www.oecd.org/science/scienceandtechnologypolicy/49344626.pdf (accessed 4 June 2012)

7. Siegfried N, Steinhausen K, Ren J, Cazap E, Melien O. Training, infrastructure and patient involvement, OECD GSF Working Group. Global core competencies for clinical trials. The Lancet 2012; in press. 